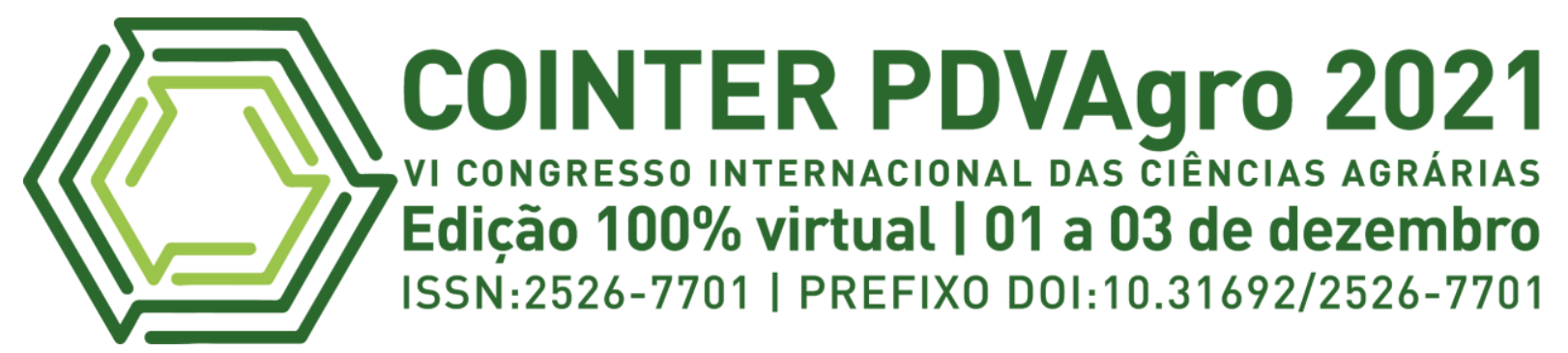

\title{
POTENCIAL DO USO DE ARROZ SEQUEIRO EM NAVIRAÍ - MS: SELEÇÃO DE VARIEDADES E MANEJO DA CULTURA
}

\section{USO POTENCIAL DEL ARROZ DE SECANO EN NAVIRAÍ - MS: SELECCIÓN DE VARIEDADES Y MANEJO DEL CULTIVO}

\section{POTENTIAL OF UPLAND RICE IN NAVIRAÍ-MS: SELECTION OF VARIETIES AND MANAGEMENT OF THE CULTURE}

\author{
Apresentação: Comunicação Oral \\ Leandro Martins Ferreira ${ }^{1}$; Caroline Aparecida Dias da Silva ${ }^{2}$; Juanita Aparecida Silva Pereira ${ }^{3}$; Priscila \\ Gonzales Figueiredo ${ }^{4}$; Cristiana Maia de Oliveira ${ }^{5}$
}

\begin{abstract}
RESUMO
O cultivo de arroz está presente em todos os continentes e é básico na alimentação de 2,4 bilhões de pessoas. O Brasil destaca-se na produção e exportação deste cereal que tem grande relevância no contexto nacional, o estado de Mato Grosso do Sul está dentre as regiões produtoras de arroz com rendimento médio previsto de $6.427 \mathrm{~kg} / \mathrm{ha}$, sendo considerado um cultivo típico da agricultura familiar. Atualmente a demanda de qualidade do grão vem crescendo, o que expõe uma grande falta de pesquisa para recomendação de cultivares, além de estudo de cultivares adaptadas para as regiões ou melhoramento genético para as mesmas. O objetivo deste trabalho foi selecionar uma variedade de arroz de sequeiro que apresente melhor adaptação e produção na região de Naviraí, MS. O experimento foi conduzido na área experimental do Instituto Federal de Mato Grosso do Sul, Campus de Naviraí. O delineamento experimental foi em blocos casualizados com 4 blocos e 10 parcelas contendo 20 plantas cada, totalizando 40 parcelas experimentais. Foram utilizadas dez variedades de arroz de sequeiro: Quebra Cacho, Catetão, Manteiga, Palha Murcha, Três Meses, Piauí, Sempre Verde, Mira, Bico Ganga e Prata Ligeiro. Ao final do ciclo, as plantas foram colhidas e determinados os parâmetros de produtividade. Foram também analisados dados de temperatura, precipitação e umidade relativa durante a condução do experimento. A variedade Quebra Cacho se destacou apresentando maior produtividade, $5000 \mathrm{Kg} / \mathrm{ha}$ e foi selecionada como a mais adaptável para as condições desse experimento.
\end{abstract}

DOI: https://doi.org/10.31692/2526-7701.VICOINTERPDVAgro.0273

Palavras-Chave: Cereais, Oryza sativa L., Seleção de Variedades.

\section{RESUMEN}

El cultivo del arroz está presente en todos los continentes y es un alimento básico para 2.400 millones de personas. Brasil se destaca en la producción y exportación de este cereal que tiene gran relevancia en el contexto nacional, el estado de Mato Grosso do Sul se encuentra entre las regiones productoras de arroz con un rendimiento promedio de $6.427 \mathrm{~kg} / \mathrm{ha}$, y es considerado un cultivo típico de la agricultura familiar. En la actualidad, la demanda de calidad del grano ha ido en aumento, lo que expone una gran

\footnotetext{
${ }^{1}$ Agronomia, IFSudesteMG, leandro.ferreira@ifsudestemg.edu.br

2 Agronomia, IFMS, caroline.silva8@estudante.ifms.edu.br

3 Agronomia, IFMS, juanita.pereira@ estudante.ifms.edu.br

${ }^{4}$ Agronomia, IFMS, priscila.figueiredo@ifms.edu.br

${ }^{5}$ Doutora, IFMS, cristiana.oliveira@ifms.edu.br
} 
falta de investigación para recomendar cultivares, así como el estudio de cultivares adaptados a las regiones o la mejora genética de los mismos. El objetivo de este trabajo fue seleccionar una variedad de arroz de secano que presente mejor adaptación y producción en la región de Naviraí, MS. El experimento se realizó en el área experimental del Instituto Federal de Mato Grosso do Sul, Campus Naviraí. El diseño experimental fue en bloques aleatorios con cuatro bloques y 10 parcelas que contenían 20 plantas cada una, totalizando 40 parcelas experimentales. Se utilizaron diez variedades de arroz de secano: Quebra Cacho, Catetão, Manteiga, Palha Murcha, Três Meses, Piauí, Sempre Verde, Mira, Bico Ganga y Prata Ligeiro. Al final del ciclo, se cosecharon las plantas y se determinaron los parámetros de productividad. También se analizaron los datos de temperatura, precipitación y humedad relativa durante el transcurso del experimento. La variedad Quebra Cacho destacó con el mayor rendimiento, $5000 \mathrm{~kg} / \mathrm{ha}$ y fue seleccionada el más adaptable a las condiciones de este experimento.

Palabras Clave: Cereales, Oryza sativa L., Selección de variedades.

\section{ABSTRACT}

Rice cultivation is present on all continents and is a staple food for 2.4 billion people. Brazil stands out in the production and export of this cereal which has great relevance in the national context, the state of Mato Grosso do Sul is among the producing regions of rice with an average yield of $6,427 \mathrm{~kg} / \mathrm{ha}$, and is considered a typical crop of family farming. Currently, the demand for grain quality has been growing, which exposes a great lack of research to recommend cultivars, as well as the study of cultivars adapted to the regions or genetic improvement for them. The aim of this work was to select an upland rice variety that presents better adaptation and production in the region of Naviraí, MS. The experiment was conducted in the experimental area of the Federal Institute of Mato Grosso do Sul, Naviraí Campus. The experimental design was in randomized blocks with four blocks and 10 plots containing 20 plants each, totaling 40 experimental plots. Ten upland rice varieties were used: Quebra Cacho, Catetão, Manteiga, Palha Murcha, Três Meses, Piauí, Sempre Verde, Mira, Bico Ganga and Prata Ligeiro. At the end of the cycle, the plants were harvested and the productivity parameters were determined. Temperature, precipitation and relative humidity data were also analyzed during the course of the experiment. Quebra Cacho variety stood out with the highest yield, $5000 \mathrm{~kg} / \mathrm{ha}$ and was selected as the most adapted to the experiment conditions.

Keywords: Cereals, Oryza sativa L., Selection of varieties.

\section{INTRODUÇÃO}

O arroz (Oryza sativa L.) está presente em todos os continentes é básico na alimentação de 2,4 bilhões de pessoas, além de fornecer a maior parte da renda principal para milhões de propriedades rurais, com uma produção mundial de 746 milhões de toneladas em uma área de 165 milhões de hectares (ha) e uma produtividade média de $4.527 \mathrm{~kg} / \mathrm{ha}$ (TRAVERSATEJERO; BORTOLOTTO-CANTARELLI, 2021).

É um alimento de valor nutricional elevado, destacando-se na constituição da dieta básica dos seres humanos. Apresenta grande fonte energética, rico em proteínas e sais minerais como fosfato, ferro e cálcio, vitaminas do complexo B, além de fornecer carboidratos, a proteína se espalha pelo grão inteiro, tornando-o de fácil digestão (RIBEIRO et al., 2018).

Segundo Rocha et al. (2017), o Brasil destaca-se na produção e exportação deste cereal, a maior parcela de sua produção é oriunda do cultivo nos agroecossistemas de várzeas, sendo a região Sul, principalmente os estados do Rio Grande do Sul e Santa Catarina responsáveis por cerca de $75 \%$ da produção nacional, através do sistema irrigado. Já o restante da produção 
concentra-se nos estados do Mato Grosso, Maranhão e Roraima com o cultivo de arroz sequeiro (PRESOTTO; MARTINELLI, 2019), na qual apresenta significativa relevância no contexto nacional, principalmente por ser um produto típico da agricultura familiar (ROCHA et al., 2017).

É importante destacar que dentre as regiões produtoras de arroz, Mato Grosso do Sul participa com uma área de colheita de 15.342 ha, estimando-se uma produtividade de 98.608 toneladas e rendimento médio previsto de $6.427 \mathrm{~kg} / \mathrm{hectares}$. A produção projetada brasileira de arroz para 2026/27 é de 12,6 milhões de toneladas, e um consumo de 11,5 milhões de toneladas (BELARMINO et al., 2018).

O arroz de terras altas, ocupando apenas $27,3 \%$ da área total de arroz cultivada no Brasil, contribui com aproximadamente $10 \%$ de toda produção nacional do cereal. Contudo, devido à baixa disponibilidade de água no processo de irrigação e pela demanda do consumo humano e industrial, o cultivo do arroz de terras altas vem crescendo, alcançando grande importância mundial (DIAS, 2018).

Em relação à adubação a cultura é altamente dependente, principalmente de nitrogênio e fósforo, para alcançar o máximo de produtividade, dessa forma a maior parte dos adubos utilizados são minerais. A prática de utilizar adubos orgânicos disponíveis na região ou até mesmo produzidos pelo próprio agricultor ainda é limitado, muitas das vezes devido ao pouco conhecimento sobre a funcionalidade.

Apesar disso, a utilização de adubação orgânica pode constituir uma forma de elevar o potencial produtivo da área e reduzir a demanda por fertilizantes minerais ao qual possuem elevado custo (MACHADO et al., 1983). Diante deste contexto, este trabalho teve como objetivo a seleção de uma variedade de arroz que apresentar maior produção e adaptação à região com o intuito de viabilizar a produção de arroz sequeiro no município de Naviraí-MS.

\section{FUNDAMENTAÇÃO TEÓRICA}

\section{Importância da Cultura do Arroz}

O arroz é uma cultura de grande importância econômica e social em muitos países sendo a base da alimentação de metade da população mundial (SILVA et al., 2017). Dentre a família das poáceas, a espécie Oryza sativa L. se destaca por ser a terceira maior cultura cerealífera do mundo (GARÉ et al., 2017).

Segundo Mendonça (2021), o arroz é cultivado em todas as regiões brasileiras, tendo sua maior produção no Rio Grande do Sul, foi responsável por quase $80 \%$ da oferta nacional 
POTENCIAL DO USO DE ARROZ SEQUEIRO EM NAVIRAÍ-MS

em 2020. A região Sul do pais obteve uma produção de mais de 9 milhões de toneladas.

São considerados dois grandes ecossistemas para a cultura, que são o de várzeas e o de terras altas, englobando todos os sistemas de cultivo de arroz no país, sendo os principais o irrigado por inundação e o de terras altas. Esse último é caracterizado pela condição aeróbica de desenvolvimento da raiz da planta, ao passo que, sob condições de solo inundado, a consequente criação de uma condição anaeróbica implica uma série de transformações que influenciam não só o desenvolvimento da planta de arroz como também a absorção de nutrientes e o manejo do solo (EMBRAPA, 2021). Segundo Mendonça et al. (2021), cerca de um terço da produção de arroz é proveniente de lavouras cultivadas no ecossistema de sequeiro (terras altas) e correspondem a dois terços da área total cultivada com o cereal.

No ano de 2018, a área plantada de arroz no Brasil foi equivalente a 1,87 milhão de ha, com uma produção total de 11,74 milhões de toneladas e rendimento médio de 6,28 t.ha-1 (EMBRAPA, 2019). A maior parte desta área e o rendimento médio apresentado se referem à produção proporcional no sistema irrigado. O sistema de sequeiro foi cultivado em cerca 480 mil ha neste ano, com uma produção estimada em 1,13 milhão toneladas e um rendimento médio de 2,30 t.ha-1 (MAGHELLY, 2020).

\section{Manejo da cultura}

O arroz é uma cultura bastante versátil, por adaptar-se a diversos tipos de solo e clima. De acordo com as condições climáticas de cada região produtora no Brasil, a semeadura do arroz ocorre entre os meses de agosto e janeiro e a colheita, entre os meses de novembro e maio. A distribuição das principais áreas plantadas com arroz de sequeiro está localizada, principalmente, no Centro-Oeste e no Nordeste do Brasil, zonas de clima tropical. Já no sistema irrigado, tanto área plantada, quanto rendimento médio e produção relativa, o predomínio é na Região Sul do país (MOURA; LANDAU, 2020).

O sistema irrigado demanda conhecimento do rizicultor (produtor de arroz), manejo, preparo do solo, adubação, sementes, entre outros. Apresentando alto custo de investimento no preparo da terra e insumos. O sistema sequeiro, requisita poucos insumos constituindo baixo custo de investimento inicial. Difere-se do arroz irrigado, sendo que na maior parte é realizado com a terra seca. (BELARMINO et al., 2018).

\section{Desafios para a produção}

A produtividade das culturas agrícolas é negativamente influenciada por uma grande gama de fatores ambientais. Estresses abióticos são as primeiras causas de redução de 
crescimento e produtividade das culturas, e entre esses, seca, salinidade, temperatura, toxidez por alumínio, alagamento, poluição e radiação estão entre os mais frequentes. Estima-se que os estresses abióticos podem reduzir a produtividade das culturas em até 70\% (FERREIRA, 2017).

Dentre os elementos meteorológicos, a temperatura é um dos componentes climáticos que mais interferem no desenvolvimento do arroz, uma vez que, quando ela é baixa $\left(<17^{\circ} \mathrm{C}\right)$ pode acarretar o abortamento de flores (esterilidade). Além da má germinação, retarda o processo de crescimento e reduz o número de perfilhos. São igualmente prejudiciais temperaturas acima de $40^{\circ} \mathrm{C}$ (JANUARIO et al., 2018).

Embora a cultura do arroz de sequeiro seja pouco exigente em insumos, vem-se buscando a adoção de novas técnicas que possa garantir consideráveis níveis produtivos à cultura, possivelmente em consequência do processo de modernização e racionalização da agricultura, o uso de adubação adequada, bem como outros fatores, tem se constituindo importante para o aumento da produtividade (ROCHA et al, 2017).

\section{Seleção de variedades e melhoramento genético}

Atualmente, vem crescendo a demanda por qualidade de grão no arroz-de-sequeiro. As cultivares recomendadas apresentam grãos do tipo longo, porém espesso, típico das cultivares tradicionais de arroz-de-sequeiro (LOPES; CORREA ,2002).

A ausência de cultivares recomendadas reflete uma importante lacuna na pesquisa e na valorização das variedades tradicionais de arroz de sequeiro conservadas pelos agricultores familiares. Além disso, cultivares sem recomendação oficial apresentam restrições na comercialização, financiamento da lavoura, seguro agrícola e aquisição de sementes, limitando as possibilidades de os agricultores expandirem suas áreas cultivadas e, eventualmente, comercializarem formalmente excedentes de produção, inclusive em programas governamentais de valorização da agricultura familiar (MAGHELLY,2020).

Sabe-se que o processo de melhoramento genético de plantas demanda muito tempo, investimento e mão de obra, desta forma, são extremamente necessários o emprego de várias ferramentas ao longo dos processos de avaliação e seleção de genótipos que visam auxiliar o ganho genético após as gerações. Entre estas ferramentas estão os estudos para obtenção das estimativas de parâmetros genéticos e fenotípicos, tais como herdabilidade, herança genética, efeito materno, correlações genéticas e fenotípicas e ganhos esperados com a seleção, sendo fundamentais, pois podem auxiliar imensamente na tomada de decisões pelo pesquisado (FACHINELLO,2021). 
O desenvolvimento de cultivares de arroz de terras altas tem forte apelo social, pois dificilmente será possível atender à crescente demanda por alimentos, com a utilização oriunda somente do sistema de produção irrigado. A estimativa, interpretação e compreensão dos parâmetros genéticos de produção irrigado. A estimativa, interpretação e compreensão dos parâmetros genéticos da população trabalhada, assim como a avaliação de seu processo genético, permitem o estabelecimento de procedimentos a serem adotados na condução do programa de melhoramento (LIMA et al., 2020).

\section{METODOLOGIA}

O experimento foi conduzido na área experimental do IFMS, Campus Naviraí. As sementes que foram utilizadas são provenientes do banco de sementes de variedades de arroz de sequeiro da Universidade Federal Rural do Rio de Janeiro (UFRRJ). Essas variedades são tradicionalmente cultivadas no Maranhão por agricultores familiares. As variedades utilizadas foram Quebra Cacho, Catetão, Manteiga, Palha Murcha, Três Meses, Piauí, Sempre Verde, Mira, Bico Ganga e Prata Ligeiro.

As sementes das variedades foram semeadas diretamente no solo. A área do experimento foi preparada através da calagem de manutenção para correção da acidez do solo na dose de 4 ton/ha de acordo com análise de solo e, posteriormente, foi incorporado a $20 \mathrm{~cm}$ de profundidade com o uso da enxada rotativa. As plantas foram conduzidas no sistema de sequeiro e o manejo da irrigação, plantas daninhas e insetos praga foram realizados ao longo do ciclo da cultura.

Ao final do ciclo, foram coletadas 4 plantas centrais de cada parcela para determinação dos componentes de produtividade. Foram determinados nas plantas coletadas: o tamanho da planta, número de perfilhos por planta, número de panículas por planta, peso de cem grãos, número de grãos cheios e chochos, peso seco da planta e produtividade. $O$ índice de colheita de grãos (IC) foi realizado a partir da razão entre a massa de grãos cheios pela massa seca da planta.

O delineamento experimental realizado foi em blocos ao acaso, com 4 blocos e 10 parcelas $\left(2,0 \mathrm{~m}^{2} /\right.$ parcela) contendo 20 plantas cada. Os dados foram submetidos a teste de normalidade (teste de Lilliefors) e homogeneidade das variâncias (teste de Cochran). Subsequentemente, os dados foram submetidos a análise de variância pelo teste $F(p<0,05)$ e as médias agrupadas pelo teste de Scott-knott $(\mathrm{p}<0,05)$ utilizando o software Sisvar (Ferreira, 2011). A análise de correlação foi realizada utilizando a ferramenta de análise de dados do Excel. Os gráficos também foram feitos utilizando o Excel. 
Os dados relacionados à temperatura, precipitação e umidade relativa foram coletados da estação meteorológica mais próxima à Naviraí, sendo utilizada a de Itaquiraí, pelo site do Instituto Nacional de Meteorologia (INMET). O período selecionado foi do mês de Novembro do ano de 2019 ao mês de Abril do ano de 2021, período em que foi realizado o experimento.

\section{RESULTADOS E DISCUSSÃO}

Dentre as 10 variedades de arroz de sequeiro selecionadas para o experimento apenas seis produziram e prosseguiram para análise dos dados, sendo elas: Bico Ganga, Prata Ligeiro, Catetão, Quebra Cacho, Piauí e Manteiga. As condições climáticas e o déficit hídrico influenciaram na produtividade dessas cultivares, bem como o ciclo muito tardio (>150 dias) que elas desenvolveram, de modo que três praticamente não produziram: Sempre Verde, Palha Murcha e Mira (Tabela 1).

Tabela1. Classificação das variedades de arroz de acordo com o ciclo de desenvolvimento, Borém \& Rangel, 2015.

\begin{tabular}{ccc}
\hline Variedades & $\begin{array}{c}\text { Ciclo } \\
\text { (Dias) }\end{array}$ & $\begin{array}{c}\text { Grupo de maturação } \\
\text { (Borém \& Rangel, 2015) }\end{array}$ \\
\hline Bico Ganga & 142 & Tardio \\
Prata ligeiro & 142 & Tardio \\
Catetão & 142 & Tardio \\
Quebra Cacho & 142 & Tardio \\
Piauí & 157 & Muito tardio \\
Manteiga & 142 & Tardio \\
Sempre verde & 176 & Muito tardio \\
Palha murcha & 172 & Muito tardio \\
Mira & 176 & Muito tardio \\
\hline
\end{tabular}

Fonte: Própria (2021).

Segundo Borém \& Rangel (2015) as cultivares de arroz podem ser classificadas de acordo com seu ciclo de desenvolvimento nos seguintes grupos: superprecoce (menor de 105 dias), precoces (entre 106 e 120 dias), médios (entre 121 e 135 dias), tardios (entre 136 e 150 dias) e muito tardios (mais que 150 dias).

De acordo com a figura 1 , a média da temperatura máxima se manteve acima de $25^{\circ} \mathrm{C} \mathrm{e}$ a temperatura mínima por volta dos $23{ }^{\circ} \mathrm{C}$ durante os meses de novembro a abril. A precipitação teve uma média de $180 \mathrm{~mm}$, onde o mês que mais choveu foi janeiro. A umidade relativa do ar 


\section{POTENCIAL DO USO DE ARROZ SEQUEIRO EM NAVIRAÍ-MS}

(Figura 2) durante esses meses teve uma média de $72 \%$, onde aliado a colheita tardia, podem ter afetado a produtividade dos grãos.

Em relação aos parâmetros de produtividade avaliados a análise global de correlações (Tabela 2) permitiu observar que o tamanho das plantas interferiu negativamente na massa de 100 grãos com valor de $-0,46$. Este resultado sugere que as plantas investiram mais no crescimento vegetativo em detrimento do crescimento reprodutivo e enchimento de grãos, de modo que as plantas mais altas tiveram um menor enchimento de grãos.

Tabela 2: Análise de correlação geral dos dados obtidos do experimento de campo com as seis variedades de arroz selecionadas para prosseguimento das análises.

\begin{tabular}{|c|c|c|c|c|c|c|c|c|c|c|c|}
\hline & Tamanho & Perfilho & Panícula & $\begin{array}{c}\text { Folh } \\
\mathrm{a} \\
\end{array}$ & $\begin{array}{c}\text { Colm } \\
\mathrm{o}\end{array}$ & Parte A. & $100 \mathrm{gr}$ & Produção & $\begin{array}{l}\text { Est. } \\
\text { E. }\end{array}$ & I.C & Produt. \\
\hline Tamanho & 1,00 & & & & & & & & & & \\
\hline Perfilho & $-0,12$ & 1,00 & & & & & & & & & \\
\hline Panícula & $-0,23$ & 0,76 & 1,00 & & & & & & & & \\
\hline Folha & 0,23 & 0,22 & 0,30 & 1,00 & & & & & & & \\
\hline Colmo & 0,02 & 0,38 & 0,32 & 0,34 & 1,00 & & & & & & \\
\hline Parte A. & 0,10 & 0,38 & 0,38 & 0,78 & 0,85 & 1,00 & & & & & \\
\hline 100gr. & $-0,46$ & $-0,13$ & 0,07 & $-0,39$ & $-0,25$ & $-0,38$ & 1,00 & & & & \\
\hline Produção & $-0,34$ & 0,29 & 0,54 & 0,18 & $-0,05$ & 0,07 & 0,47 & 1,00 & & & \\
\hline Est. E. & 0,05 & 0,21 & $-0,07$ & $-0,20$ & $-0,13$ & $-0,20$ & 0,10 & $-0,30$ & 1,00 & & \\
\hline I.C & $-0,29$ & 0,12 & 0,25 & $-0,32$ & $-0,50$ & $-0,51$ & 0,48 & 0,72 & $-0,11$ & $\begin{array}{c}1,0 \\
0\end{array}$ & \\
\hline Produt. & $-0,34$ & 0,29 & 0,54 & 0,18 & $-0,0$ & 0,07 & 0,47 & 1,00 & $-0,30$ & $\begin{array}{c}, 1 \\
2\end{array}$ & 1,00 \\
\hline
\end{tabular}

Houve uma correlação positiva de 0,76 de perfilho com a panícula, ou seja, o crescimento de ambos foi alinhado. Isso significa que na maioria das variedades os perfilhos foram reprodutivos, onde o número de panículas interferiu positivamente na produção, com um valor de 0,54 de maneira que a maioria das panículas produziram grãos cheios.

A massa de parte aérea se correlacionou negativamente principalmente com o Índice de colheita (-0,51). Este resultado sugere que aquelas variedades que investiram mais em parte aérea apresentaram menor colheita de grãos cheios. Em contrapartida, as que cresceram menos tiveram maior colheita, como poderá ser visto nos resultados obtidos adiante. Segundo Ferraz (1987) a capacidade produtiva de uma planta de arroz depende, além da sua eficiência fotossintética, da rapidez com que os fotossintatos são canalizados para as espiguetas da panícula. A eficiência desse transporte é dada pela relação massa seca dos grãos/massa seca 
total da planta, uma importante variável que visa verificar o equilíbrio entre massa vegetal produzida e grãos colhidos.

A massa de 100 grãos apresentou correlação, ainda que relativamente fraca, com a produtividade $(0,47)$. Soares et al. (1990) também notaram correlação positiva e significativa entre produtividade de grãos e massa de 100 grãos com um valor positivo de 0,76 . Este resultado demonstra a importância desse parâmetro para selecionar variedades mais produtivas, sendo essas características consideradas prioritárias em programas de melhoramento de arroz que visem obter cultivares mais produtivas. Rangel et al. (1980) também constataram correlação positiva e significativa entre produtividade de grãos e porcentagem de grãos cheios, assim como observado em nosso trabalho.

Segundo os dados de massa de folhas (tabela 3), a variedade Manteiga apresentou o maior valor, seguida da Piaú, as quais não se diferiram estatisticamente. As demais variedades apresentaram massa de folhas um pouco menor não diferindo estatisticamente entre si.

Tabela 3: Massa fresca de folhas, colmo e parte aérea das variedades de arroz de sequeiro cultivadas na área experimental do IFMS - Campus Naviraí.

\begin{tabular}{lccc}
\hline Variedades & Folha & Colmo & Parte aérea \\
\hline & \multicolumn{3}{c}{$-----g$---- } \\
Bico Ganga & 28,0B* & $52,2 \mathrm{~A}$ & $80,2 \mathrm{~A}$ \\
Catetão & 29,0B & $38,5 \mathrm{~B}$ & $67,5 \mathrm{~B}$ \\
Manteiga & $53,3 \mathrm{~A}$ & $25,6 \mathrm{~B}$ & $78,9 \mathrm{~A}$ \\
Piauí & $43,1 \mathrm{~A}$ & $60,5 \mathrm{~A}$ & $103,7 \mathrm{~A}$ \\
Prata Ligeiro & $23,9 \mathrm{~B}$ & $35,2 \mathrm{~B}$ & $59,1 \mathrm{~B}$ \\
Quebra Cacho & $21,8 \mathrm{~B}$ & $42,8 \mathrm{~B}$ & $64,5 \mathrm{~B}$ \\
$\quad$ C.V\% & 19,3 & 23,3 & 19,4 \\
\hline
\end{tabular}

* Médias seguidas da mesma letra maiúscula na coluna não diferem estatisticamente pelo teste de Scott-Knott, $p \leq$ 0,05 de significância.

Fonte: Própria (2021).

A variedade Piauí produziu uma massa de colmo significativa, e consequentemente apresentou o maior valor de massa de parte aérea. Porém, apesar de ter tido um alto investimento em massa verde não foi refletido na sua produtividade, onde veremos nas tabelas abaixo. A menor massa de colmo foi registrada pela variedade Manteiga. Com relação a parte aérea, pode-se observar que as variedades Piaú, Bico Ganga e Manteiga apresentaram os maiores valores de massa indicando que essas variedades investiram no crescimento da parte aérea. As variedades Catetão, Prata Ligeiro e Quebra Cacho apresentaram massa significativamente menor, não diferindo entre si. 
De acordo com a tabela 4, a variedade Bico Ganga apresentou o maior crescimento com uma média de 98,5 cm se destacando das demais variedades. Em seguida, observa-se Piauí (89,8 cm), Catetão (86,6 cm), Quebra Cacho (78 cm), Prata Ligeiro $(76,3 \mathrm{~cm})$ e, por último, a Manteiga (74,3 cm). A variedade Manteiga apesar de ter tido uma grande massa de folhas, não refletiu no seu crescimento (Tabela 3 ).

Tabela 4: Parâmetros de produtividade das variedades de arroz de sequeiro cultivadas na área experimental do IFMS - Campus Naviraí.

\begin{tabular}{cccccccc}
\hline \multirow{2}{*}{ Variedades } & Tamanho & Perfilhos & Panículas & 100grãos & Produção & Esterilidade & I.C \\
\hline & $c m$ & \multicolumn{2}{c}{--- número --- } & $-------g$ & ------ & $\%$ & \\
Bico Ganga & $98,5 \mathrm{~A}^{*}$ & $30,3 \mathrm{~B}$ & $17,5 \mathrm{~B}$ & $1,1 \mathrm{C}$ & $6,4 \mathrm{C}$ & $80,2 \mathrm{~A}$ & $0,1 \mathrm{C}$ \\
Catetão & $86,6 \mathrm{~B}$ & $20,8 \mathrm{C}$ & $18,8 \mathrm{~B}$ & $2,5 \mathrm{~A}$ & $20,6 \mathrm{~B}$ & $40,2 \mathrm{~B}$ & $0,3 \mathrm{~B}$ \\
Manteiga & $74,3 \mathrm{C}$ & $24,5 \mathrm{C}$ & $21,7 \mathrm{~B}$ & $1,5 \mathrm{~B}$ & $20,6 \mathrm{~B}$ & $59,6 \mathrm{~A}$ & $0,3 \mathrm{~B}$ \\
Piauí & $89,8 \mathrm{~B}$ & $28,1 \mathrm{~B}$ & $25,8 \mathrm{~A}$ & $0,8 \mathrm{D}$ & $11,5 \mathrm{C}$ & $33,0 \mathrm{~B}$ & $0,1 \mathrm{C}$ \\
Prata Lig. & $76,3 \mathrm{C}$ & $18,0 \mathrm{C}$ & $19,6 \mathrm{~B}$ & $2,4 \mathrm{~A}$ & $12,1 \mathrm{C}$ & $64,1 \mathrm{~A}$ & $0,2 \mathrm{~B}$ \\
Quebra C. & $78,0 \mathrm{C}$ & $39,0 \mathrm{~A}$ & $33,6 \mathrm{~A}$ & $2,5 \mathrm{~A}$ & $34,0 \mathrm{~A}$ & $63,5 \mathrm{~A}$ & $0,9 \mathrm{~A}$ \\
C.V\% & 4,3 & 15,7 & 18,5 & 11,5 & 27,4 & 18,8 & 21,8 \\
\hline
\end{tabular}

* Médias seguidas da mesma letra maiúscula na coluna não diferem estatisticamente pelo teste de Scott-Knott, $p$ $\leq 0,05$ de significância.

Fonte: Própria (2021).

A variedade Quebra Cacho foi a que produziu o maior número de perfilhos e, consequentemente, apresentou maior número de panículas. A variedade Prata Ligeiro, por outro lado, foi a que menos produziu perfilhos. A maior produção de panículas foi observada pelas variedades Quebra Cacho e Piauí seguido das demais variedades. A massa de cem grãos foi maior nas variedades Catetão, Prata Ligeiro e Quebra Cacho. Esses dados da massa de 100 grãos interferem no rendimento de grãos, além de ser uma característica relacionada à qualidade comercial das cultivares. Com relação a produção, pode-se notar que a variedade Quebra Cacho se destacou com a maior produção seguido das variedades Catetão e Manteiga que não diferiram entre si e de Bico Ganga, Piauí e Prata Ligeiro.

Dentre os parâmetros analisados, podemos observar que a porcentagem de esterilidade das espiguetas foi alta em todas as variedades, mesmo as que produziram mais. A esterilidade da espigueta representa a quantidade de grãos chochos pela quantidade total de grãos produzidos. A intensidade da ocorrência de esterilidade dos grãos pode variar de acordo com a capacidade da planta de tolerar o estresse conforme observado por SINGH e SINGH, (2013) e RAMAN et al. (2012). Variedades tolerantes tendem a apresentar um melhor status hídrico que influencia diretamente no enchimento, esterilidade dos grãos e produtividade (LIU et al., 2008). 
A cultivar Bico Ganga, apresentou a maior esterilidade, $80 \%$. O segundo grupo, com maior esterilidade de espiguetas, é composto pelas cultivares Prata Ligeiro, Quebra Cacho e Manteiga, este comportamento pode ser explicado pelo ambiente de sequeiro em que foram submetidas, altas temperaturas e a falta de agua pode ter sido o principal fator, porque apesar de terem sido plantadas na época das águas (Novembro), algumas semanas foram secas e quentes. De acordo com Yoshida (1981), alta esterilidade de espiguetas pode ocorrer com temperaturas acima de $35^{\circ} \mathrm{C}$ na floração, a fase mais sensível da planta. A segunda fase mais sensível ocorre em torno de nove dias antes da floração.

A cultivar Quebra Cacho, apresentou índice de colheita de 0,9 significativamente superior aos das outras variedades. O menor índice de colheita foi de 0,1 das variedades Piauí e Bico Ganga seguido da Prata Ligeiro com 0,2, mostrando que essas variedades de arroz tiveram menor adaptabilidade ao ambiente de sequeiro em que foram cultivadas, contribuindo para seu pior comportamento produtivo, mesmo apresentando valores altos de perfilhamento.

A produtividade das variedades corrobora com os dados já apresentados de produção (Figura 2). A variedade Quebra Cacho se destaca com uma produtividade média de $5000 \mathrm{~kg} / \mathrm{ha}$. Seguido pelas variedades Catetão e Manteiga com média de $3000 \mathrm{~kg} / \mathrm{ha}$. As demais variedades Bico Ganga, Piauí e Prata Ligeiro apresentaram média de produção inferior a 2000 kg/ha. Segundo dados da Companhia Nacional de Abastecimento (Conab) 2015, a média nacional de produção de arroz cultivado no sistema de sequeiro é de $5.108 \mathrm{~kg} / \mathrm{ha}$, onde a variedade Quebra Cacho foi a que mais se aproximou desse valor.

Figura 2: Produtividade $\left(\mathrm{kg}\right.$. há $\left.{ }^{-1}\right)$ das variedades de arroz de sequeiro cultivadas na área experimental do IFMS - Campus Naviraí. Barras representam o erro padrão de 12 repetições.

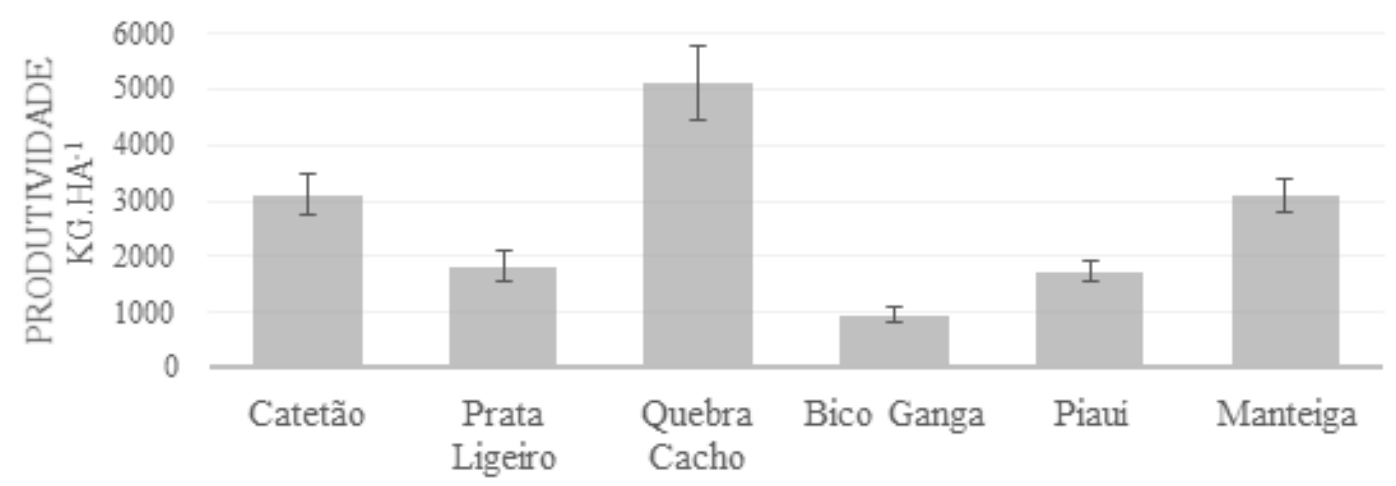

Fonte: Própria (2021). 


\section{CONCLUSÕES}

Nas condições avaliadas, a variedade Quebra Cacho se destacou chegando bem perto da média nacional da produção de arroz para o sistema de sequeiro, e se mostrou mais adaptável à região a qual foi plantada.

A realização de mais um experimento com as variedades estudadas torna-se necessário para confirmar as variedades mais adaptáveis às condições climáticas de Naviraí, MS.

\section{REFERÊNCIAS}

ARAUS, J. L.; SLAFER, G. A.; REYNOLDS, M. P.; ROYO, C. Plant breeding and drought in C3 cereals: what should we breed for? Annals of Botany, v. 89, n. 7, p. 925-940, 2002.

BELARMINO, LUIZ CLÓVIS et al. Aspectos Da Economia do Arroz Irrigado no Bioma Pampa. In: CONGRESSO SOCIEDADE BRASILEIRA DE ECONOMIA, ADMINISTRAÇÃO E SOCIOLOGIA RURAL, 56., 2018, Campinas. Artigo. Campinas: Sober, 2018 . $\quad$ v. $1, \quad$ p. $1-15 . \quad$ Disponível em: https://ainfo.cnptia.embrapa.br/digital/bitstream/item/181647/1/Belarmino-9331.pdf. Acesso em: 03 set. 2021.

BORÉM, A.; RANGEL, P. H. N. Arroz do plantio a colheita. 1 ed. Viçosa. Universidade Federal de Viçosa, 2015, v.1, p. 43-65. 242p

BOYER, H. J. Plant productivity and environment. Science, v. 218, p. 443-448, 1982. CRAMER, G. R.; URANO, K.; DELROT, S.; PEZZOTTI, M.; SHINOZAKI, K. Effects of abiotic stress on plants: a systems biology perspective. BMC plant biology, v. 11, n. 1, p. 163, 2011.

DIAS, JOÃO MÁRIO MOREIRA. Consorcio de urochloa ruziziensis em diferentes épocas de plantio com a cultura do arroz (Oryza sativa) de terras altas. 2018. $28 \mathrm{f}$. TCC (Graduação) - Curso de Agronomia, Centro Universitário de Goiás Uni-Anhanguera, Goiás, 2018.

EMBRAPA. Produção/Arroz de Terras Altas/Correção do Solo. Disponível em: https://www.embrapa.br/cultivo-do-arroz/producao/sistema-de-cultivo. Acesso em: 3 set. 2021.

FACCHINELLO, Paulo Henrique Karling. Ação gênica, parâmetros genéticos e ganho por seleção de atrubutos físicos relacionados a qualidade de grãos em arroz. 2021. 109 f. Tese (Doutorado) - Curso de Agronomia, Universidade Federal de Pelotas, Pelotas, 2021. Disponível em:

http://www.guaiaca.ufpel.edu.br/bitstream/prefix/7953/1/Tese_Paulo_Henrique_Karling_Facc hinello.pdf. Acesso em: 10 nov. 2021.

FERREIRA, D. F. Sisvar: A computer statistical analysis system. Ciência e Agrotecnologia, v. 35, n. 6, p. 1039-1042, 2011. 
FERREIRA, L. M. Características morfológicas, fisiológicas e transcriptoma em variedades de arroz (Oryza sativa $\mathrm{L}$.) contrastantes quanto a tolerância ao estresse hídrico. 2017. 110f. Tese (Doutorado em Agronomia - Ciência do Solo). Instituto de Agronomia, Universidade Federal Rural do Rio de Janeiro, Seropédica, RJ. 2017.

GARÉ, L. M.; BUZO, F. S.; ARF, O.; PORTUGAL, J. R.; SILVEIRA, T. L. S.; MEIRELLES, F. C.. Influência do thidiazuron e da inoculação com azospirillum brasilense no crescimento e produtividade do arroz de terras altas. Revista Brasileira de Engenharia de Biossistemas, v. 11, n. 4, p. 326-339, 2017.

JANUARIO, I. R.; MENEZES, R. H. N.; BONFIM, O. E. T. Análise de risco climático para semeadura do arroz no Sul do Estado do Maranhão. Revista Brasileira de Geografia Física, v. 11, n. 4, p. 1241-1250, 2018.

LAWLOR, D. W.; CORNIC, G. Photosynthetic carbon assimilation and associated metabolism in relation to water deficits in higher plants. Plant, Cell \& Environment, , v. 25, n. 2, p. 275294, fev. 2002.

LIMA, Isabela Pereira de et al. Potencial genético de linhagens de arroz de terras altas pertencentes ao programa de melhoramento da Universidade Federal de Curitiba. ano 2020, v. 6, n. 1, ed. 1, p. 1706-1713, 12 set. 2019. DOI 1034117. Disponível em: https://www.brazilianjournals.com/index.php/BRJD/article/view/6067/5403. Acesso em: 30 ago. 2021.

LIU, G.L. et al. QTL analysis of panicle neck diameter, a trait highly correlated with panicle size, under well-watered and drought conditions in rice (Oryza sativa L.). Plant Science, v. 174, n. 1, p. 71-77, jan. 2008.

LOPES, A. M.; CORREA, J. R. V.. Maravilha: Cultivar de Arroz de Sequeiro Recomendada para a Região Oeste do Estado do Pará. Belem - Pa: Infoteca, 2002. 4 p. Disponível

em: https://www.infoteca.cnptia.embrapa.br/bitstream/doc/404868/1/com.tec.74.pdf. Acesso em: 10 nov. 2021.

MACHADO, M.O.; GOMES, A.S.; TURATTI, A.L.; PAULETTO, E.A.; JUNIOR, P.S. Efeito da adubação orgânica e mineral na produção do arroz irrigado e nas propriedades químicas e físicas do solo de Pelotas. Pesquisa Agropecuária Brasileira, v. 18, n. 6, p. 583-591, 1983.

MAGHELLY, O. R. Potencial genético de variedades locais de arroz de sequeiro do oeste catarinense. 2020. 123 f. Tese (Doutorado) - Curso de Ciências, Ciências Agrárias, Universidade Federal de Santa Catarina, Florianópolis, 2020.

MAHAJANS, S; TUTEJA, N. Cold, salinity and drought stress; Na overview. Anchivesof Biochemistry and Biophycis, v. 444, n.2, p. 139- 158, 2006.

MENDONÇA, S. M. Rizobactérias multifuncionais na mitigação do déficit hídrico e da brusone foliar em arroz de terras altas. 2021. 89 f. Dissertação (Mestrado em Agronomia) Universidade Federal de Goiás, Goiânia, 2021.

LANDAU, E. C.; HIRSCH, A.; GUIMARÃES, D. P.; MOURA, L.; SANTOS, A. H. dos; 
NERY, R. N. Variação geográfica da produção de grãos e principais culturas agrícolas no Brasil em 2013. Sete Lagoas: Embrapa Milho e Sorgo, 2015. 143 p. (Embrapa Milho e Sorgo. Documentos, 182). Disponível em: . Acesso em: 19 jun. 2018.

MILHOMEM, A. L. G.; LIMA, R. H. P.; MOREIRA, L. B. Atributos agronômicos de duas cultivares de arroz vermelho, ENA AR-1601 e Virgínia, produzidos em sistema de sequeiro sob manejo orgânico no município de seropédica (RJ). In: IV SIMPÓSIO ABC, 4., 2021, Rio de Janeiro. Anais (...). Sistemas de produção e sustentabilidade agrícola: Experiências Argentina, Brasil e Cuba. Rio de Janeiro: UFRRJ, 2021. p. 1-6.

PRESOTTO, E.; MARTINELLI, G. C. Eficiência energética entre a produção de arroz no sistema de cultivo irrigado e sequeiro no Brasil. Anpec, v. 1, n. 1, p. 01-13, jan. 2019.

ROCHA, A. M. D. et al. Viabilidade econômica da produção de arroz de Terras Altas na Região Médio Norte de Mato Grosso: Um estudo de caso. Revista Espacios, Mato Grosso, v. 38, n. 3, p. 3-9, jan./2017.

SILVA, J. C.; SOARES, P. C.; RANGEL, P. H. N.; CUTRIM, V. DOS A.; CASTRO, E. DA M.; CRUZ, C. D. Correlações coeficientes de trilha de caracteres do arroz cultivado em várzea úmida ou sob irrigação com inundação contínua. Revista Ceres, v.37, n.209, p.1-15, 1990.

SINGH, A.; SHAMIM, M.; SINGH, K. N. Genotypic variation in root anatomy, starch accumulation, and protein induction in upland rice (Oryza sativa) varieties under water stress. Agricultural Research, v. 2, n. 1, p. 24-30, 2013.

SOARES, P. C.; Silva, J. C.; Rangel, P. H. N.; Cutrim, V. dos A.; Castro, E. da M.; Cruz, C. D. Correlações coeficientes de trilha de caracteres do arroz cultivado em várzea úmida ou sob irrigação com inundação contínua. Revista Ceres, v.37, n.209, p.1-15, 1990.

TRAVERSA-TEJERO, I. P.; BORTOLOTTO-CANTARELLI, R. Produção orizícola no município de São Gabriel, RS (Brasil). Journal of The Selva Andina Biosphere. Bolivia, p. 67-68. 04 jan. 2021. 